\title{
Joint venture on biochips ends in disarray
}

\section{Quirin Schiermeier, Moscow}

A successful scientific collaboration between Russia and the United States for developing microchips to process genetic information has collapsed in acrimony.

The collaboration, which involved the Engelhardt Institute of Molecular Biology (EIMB) in Moscow, the Argonne National Laboratory in Illinois and two US-based commercial partners, had provided substantial funding for the Moscow laboratory in exchange for access to its expertise in DNA chip technology.

But in recent months, financial support for the Russian laboratory has dried up as EIMB and Argonne argue over the contractual arrangements between the parties. As a result of the dispute, Andrei Mirzabekov has resigned as director of Argonne's Biochip Technology Center. In turn, Argonne has suspended the transfer to the Russian laboratory of some of the royalties it receives from the collaboration's industrial partners.

The collaboration, which began in 1995, has generated almost 40 scientific publications and 30 patents and patent applications. It also triggered a partnership with Packard
BioScience, a Connecticut-based instrument maker, and the electronics company Motorola. The companies have used research from the collaboration to develop commercial microchips based on tiny gels applied on a glass surface which can perform thousands of biological reactions within seconds, and associated instruments to process and analyse results from the chip. Researchers use the technology to detect genetic mutations and for drug design.

Motorola and Packard have contributed almost US\$20 million to the project over five years, making it one of the most successful biotechnology agreements between the US Department of Energy, which runs Argonne, and industry. About $15 \%$ of this money went to the EIMB, which also, Mirzabekov says, received funding through a licensing agreement with Argonne.

Argonne officials agree that the arrangement has been a roaring success. "This has been a true model relationship," says one. But according to Bill Ragland, a research manager at Argonne, it is now time to reduce the size of the Moscow research operation supported by the collaboration.

\section{It's a dog's life for Siberian foxes}

Bryon MacWilliams, Moscow

A unique project in Siberia that has helped researchers understand how animals become domesticated could soon expire from lack of funds.

Researchers at the Institute of Cytology and Genetics in Novosibirsk have compressed into decades a process that might otherwise require thousands of years. Through intense selective breeding, they have turned the silver fox (Vulpes vulpes) into an amiable, tail-wagging house pet.

The work, started in 1959 by the late geneticist Dmitry Belyaev, has

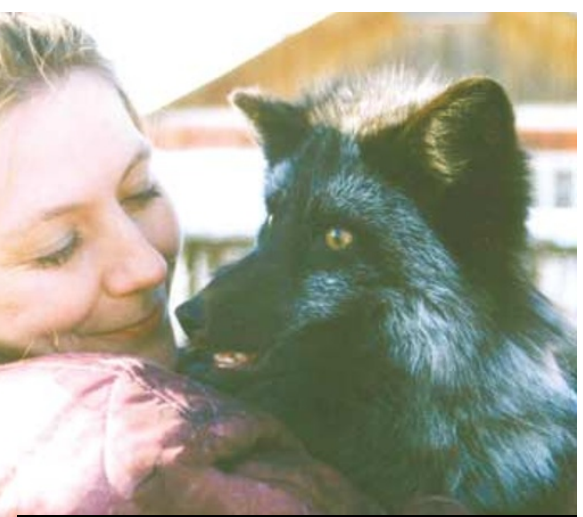

Tail of woe: lack of money leaves the project to domesticate foxes facing an uncertain future. demonstrated the close links between behavioural and developmental genetics.

The silver fox - known as the red fox in the United States - is closely related to the dog, but had never been domesticated. The 45,000 foxes so far involved in the Siberian project were chosen by researchers for their propensity to being tamed.

The selection process resulted in the emergence of traits in physiology, morphology and behaviour that are most noticeable in the changes in coat colour and the presence of floppy ears and curled tails.

But the institute lacks the $\$ 10,000$ a year it needs to keep the project going. "This is the only kind of experiment of its kind in the world," says Ludmila Trut, head of the research group at the institute. "It would be a tragedy if it were to wither."

The research "is really important because evolutionary change in behaviour is very hard to study," says Deborah Goodwin, deputy director of the Anthrozoology Institute at the University of Southampton in Britain.

The population of breeding foxes has been reduced from 700 to 100 since 1996 and the staff, too, is declining. The project is now overseen by seven researchers of retirement age.

http://www.bionet.nsc.ru/ICIG

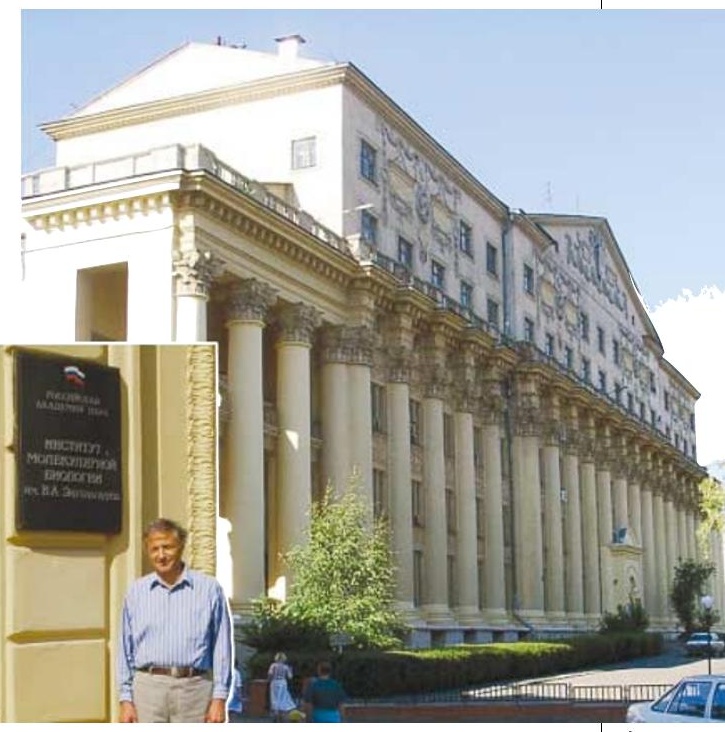

Moving on: director Andrei Mirzabekov (inset) is looking for new partners for Moscow's Engelhardt Institute of Molecular Biology.

Mirzabekov claims that some US officials have turned sour on the arrangement because of security concerns about the possible use of biochip technology in detecting biological warfare agents. Argonne officials deny that this has any connection with their decision.

According to Argonne, royalty payments of about $\$ 500,000$ for the year 2000 have been stopped because of contractual disagreements over intellectual property rights on microchip technology. The technology was initially described by a team at the Moscow lab in the 1980s. Argonne rejects Mirzabekov's claim that rights for the technology, which was subsequently developed by the joint venture, should now revert back to the EIMB.

Argonne officials say they are keen to transfer the outstanding money, but first want Mirzabekov to sign a contract assuring them that he will continue to abide by earlier financial agreements. Mirzabekov is unhappy with the contract, saying he already has one, and that Argonne is effectively seeking to renegotiate it. "It makes us very worried about the future, thinking that Argonne could depart from other contracts as well," he says.

Mirzabekov says he has hired lawyers in the United States, but cannot afford to fight a lengthy legal battle with the US lab. He hopes instead that the Russian science ministry will settle the case directly with the US Department of Energy.

Mirzabekov is now searching for new partners in the United States or Western Europe. He hopes to use biochips to detect drug-resistant strains of tuberculosis - a growing health problem in Russia. 